ReVISTA INTERNACIONAL dE Sociología (RIS) Monográfico sobre asociacionismo e inmigración

Vol. 71, EXTRA 1, 11-14, Junio 2013 ISSN: 0034-9712; eISSN: 1988-429X

DOI:10.3989/ris.2012.09.02

\title{
INTRODUCCIÓN METODOLÓGICA
}

\section{METHODOLOGICAL INTRODUCTION}

\author{
JoRDI GARRETA BoCHACA jgarreta@geosoc.udl.cat \\ Universidad de Lleida. España
}

La inmigración que ha recibido España se ha caracterizado, entre otras cuestiones, por su rápido crecimiento, especialmente en la primera década del siglo XXI, y diversificación de orígenes. Y también, con el paso del tiempo, por la creación de asociaciones y centros religiosos, indicador de instalación y de organización. Esta creciente presencia de asociaciones formadas por personas extranjeras y la interacción que llevan a cabo con las administraciones y otras organizaciones del tercer sector nos hizo interesar por analizar su evolución y su situación actual.

El monográfico Asociacionismo e inmigración se ha confeccionado a partir de los resultados obtenidos en el proyecto "Asociacionismo e inmigración africana: funciones latentes y manifiestas", financiado por el Ministerio de Ciencia e Innovación (CSO2008- 01122/SOCl), que se realizó entre 2008 y 2011 en las comunidades autónomas de Cataluña, Comunidad Valenciana y Navarra. De forma sintética, los objetivos del proyecto y ahora de este monográfico son: analizar los procesos de génesis y desarrollo del asociacionismo entre inmigrantes de origen africano; definir la estructura, las funciones, las necesidades y las imágenes de las asociaciones; profundizar en el grado de reconocimiento y utilidad atribuidos al asociacionismo y en los factores que influyen en que las administraciones públicas y otras instituciones y entidades que trabajan "por" y "para" los inmigrantes consideren, o no, que se trata de interlocutores a quienes se debe tomar en consideración. Más allá del análisis de la documentación y bibliografía existente sobre inmigración, políticas de integración y el asociacionismo, se realizó también un trabajo empírico —que es el que los artículos siguientes presentarán temáticamente.

El proyecto se inició a finales de 2008 con la recopilación de datos sobre la evolución del fenómeno inmigratorio en las comunidades autónomas de Cataluña, Valencia y Navarra, además de detectar y reunir los registros y listados existentes de asociaciones de inmigrantes, especialmente las de personas procedentes de África.

Durante el año 2009, como trabajo empírico previo al diseño del cuestionario y los guiones, se realizaron 30 entrevistas en profundidad con carácter documental y como un primer acercamiento a la realidad del asociacionismo. Una vez diseñado el cuestionario por el equipo, se inició el trabajo empírico: una encuesta por entrevista personal a representantes de asociaciones formadas principalmente por personas de origen extranjero procedentes de África. Lo primero que hicimos fue recopilar y analizar las bases 
de datos existentes sobre estas asociaciones a nivel nacional y, especialmente, en las comunidades autónomas en las que trabajamos. De esta forma pudimos detectar que se trataba de asociaciones registradas en las diferentes administraciones (española o autonómicas) pero también que las había sin registradar a nivel oficial. Por ello, dado que los listados oficiales existentes no garantizaban que accediésemos a todo el abanico de asociaciones, procedimos a diseñar un trabajo empírico mixto que tuviera en cuenta los listados oficiales, otros registros (por ejemplo, de fundaciones) y la detección de otras asociaciones. Es decir, partiendo de los listados de asociaciones se realizaron las primeras entrevistas a sus representantes para, posteriormente, con la información que nos dieron, ir ampliando nuestro propio censo de asociaciones según el perfil de nuestro interés. Además, para asegurarnos de que la "bola de nieve" fuera lo más completa posible, contactamos con representantes de administraciones (desde las autonómicas a las locales), de sindicatos, de fundaciones y de organizaciones no gubernamentales que trabajan habitualmente con este tipo de asociaciones para completar el listado. El trabajo empírico consistió en un barrido intenso al que dedicamos cuatro meses (de septiembre a diciembre de 2009 y, durante el primer trimestre de 2010, se realizó la tabulación de los cuestionarios y el análisis estadístico), lo cual nos permitió detectar, creemos, a la mayoría de asociaciones existentes. La base de asociaciones detectadas a través de las estrategias citadas fue de 260.

Eso sí, identificarlas no aseguraba que pudiésemos entrevistar a los representantes de todas ellas. La situación de inestabilidad o los cambios de local social que tienen algunas de estas asociaciones hizo dificultoso poder localizar a algunas de ellas, a pesar de los esfuerzos realizados. Además, unas pocas no quisieron colaborar en la investigación. Finalmente, la muestra de la encuesta con la que trabajamos fue de 206 representantes de asociaciones, de los cuales, el 55,3\% tenía el cargo de presidente/a; el 19,4, de secretario/a; el 4,9\%, de coordinador/a; el 4,4\%, de vocal; mientras que el resto ocupaba otros cargos o los había ocupado. Todos ellos eran personas muy conocedoras de la asociación, su funcionamiento y actuaciones, ya que este era el filtro para decidir que íbamos a realizar la entrevista.

La fase siguiente de la investigación, realizada en 2010 , se centró en la metodología cualitativa: entrevistas en profundidad, grupos de discusión e historias de vida. A partir de los guiones redactados por el equipo, se inició el trabajo empírico de esta fase. Concretamente, el trabajo consistió en 215 entrevistas en profundidad de las cuales se transcribieron y analizaron 186, dado que algunas de ellas no generaban información relevante o los informantes no habían respondido, finalmente, al perfil requerido. Los perfiles obtenidos fueron: 77 entrevistas a representantes de asociaciones de inmigrantes procedentes de África; 49 entrevistas a inmigrantes no asociados (lo que llamamos "no vinculados"); 60 entrevistas a instituciones, asociaciones proinmigrantes y otras entidades (lo que llamamos "interlocutores"). Respecto a las historias de vida de líderes asociativos, se realizaron 20, así como 8 grupos mixtos de discusión en los que participaron los diferentes perfiles citados en las entrevistas. En todos los casos se siguió el criterio de que respondieran a la diversidad de asociaciones de inmigrados de origen africano existentes y a la tipología construida en la fase cuantitativa. 
Como podrá verse en los textos, identificamos las entrevistas a partir del perfil de las mismas y utilizando acrónimos. Para la construcción de los mismos se distinguió, en primer lugar, si se trataba de una asociación, institución, administración, entidad u otro perfil de entrevista, así como si se trataba de un grupo de discusión o de una historia de vida; concretamente, en primer lugar se identifica: $A$, asociación; I, institución; $A D$, administración; E, entidad; N, no asociado; $H$, historia de vida; GD, grupo de discusión. En segundo lugar se identifica el país de origen del entrevistado: MA, Marruecos; SE, Senegal; GA, Gambia; BF, Burkina Faso; AR, Argelia; GU, República de Guinea (Conakry); E, España, A, Argentina; T, Túnez; GEC, Guinea Ecuatorial; MAU, Mauritania; NI, Nigeria; CA, Camerún; SL, Sierra Leona; GH, Ghana; y ML, Mali. En tercer lugar se identifica el sexo del entrevistado: $\mathrm{H}$, hombre; $\mathrm{M}$, mujer. En cuarto lugar la provincia en la que se ubica la asociación, entidad o persona: Barcelona, B; Tarragona, T; Lleida, LL; Girona, G; Navarra, N; Valencia, V; Alicante, A; Castellón, C. En último lugar se indica el año de realización de la entrevista, historia de vida o grupo de discusión: 2009 (09) 0 2010 (10). Eso sí, en caso de coincidencia de acrónimos se diferencian con I, II, III, IV... Así, por ejemplo, AMAHLL10 indica que se trata de una entrevista a un representante de asociación, originario de Marruecos y hombre. Además, la asociación está ubicada en Lleida y la entrevista se realizó en 2010.

La citada investigación, teórica y empírica, es la base de los siguientes ocho artículos. Aunque todos ellos con un mismo hilo conductor y relacionados, cada uno trata de una temática. El primer texto, firmado por Garreta y Llevot, realiza una primera aproximación al asociacionismo de los inmigrantes africanos describiendo sus objetivos, organización, actividades y elabora una tipología que servirá como referente para parte de los artículos siguientes. El texto de Montcusí y Albert se centra en el rol de las asociaciones en la cohesión social y la convivencia. El tercer texto, escrito por Lacomba y Giner, se fija en los no se interesan y participan en estas asociaciones. El desapego de algunas personas hacia las asociaciones que en teoría les representan es su centro de interés, especialmente los motivos de la distancia. El siguiente texto, firmado por Giró y Mata, profundiza en las estructuras organizativas de las asociaciones formadas por senegaleses. Profundizando en este perfil de asociaciones, destacan la importancia de la solidaridad en su formación y mantenimiento. El quinto texto, firmado por Mata y Giró, profundiza en la cuestión religiosa y el papel que tiene en el nacimiento y consolidación de las asociaciones formadas, principalmente, por personas procedentes de Magreb y África Subsahariana. A continuación, el texto de Molina, Samper y Mayoral analiza el liderazgo femenino en comparación al masculino a partir de diez historias de vida. Posteriormente, el texto de Llevot y Garreta profundiza en una de las actividades más importantes que realizan estas asociaciones: la mediación intercultural. Concluyendo que aunque se trata de una actividad altamente reconocida desde las asociaciones como importante, se encuentra aún en fase inicial de desarrollo. Por último, el texto de Palaudàrias y Serra presenta la actividad formativa que se realiza desde las asociaciones: temas que se abordan (lengua, religión, inserción laboral, etc.), como su orientación. Entre los ocho textos se puede comprender gran parte de lo realizado por el equipo de investigación, así como sus intereses. 
Por último, queremos agradecer al Ministerio de Ciencia e Innovación la concesión y dotación económica del proyecto. También queremos agradecer a la que ha sido un referente para todos nosotros, la Dra. Carlota Solé, que haya aceptado escribir el texto de presentación del monográfico, y a la Revista Internacional de Sociología que haya aceptado publicarlo. Además, un agradecimiento especial a las personas que han colaborado en el trabajo empírico y en la transcripción y a todos los que nos han dedicado su tiempo respondiendo a nuestras preguntas, dándonos sus opiniones y mostrándonos sus vidas.

JoRDI GARRETA BochaCA es profesor titular de sociología del Departamento de Geografía y sociología de la Universidad de Lleida. Su trabajo investigador se ha centrado en sociología de la educación (escolarización del alumnado de origen extranjero, políticas de integración y participación de las familias en la escuela) y en sociología de las migraciones (movimientos migratorios, integración, participación social). En los últimos años ha sido investigador invitado en l'Université de Montréal y en l'Ecole des Hautes Études en Sciences Sociales (París).

RECIBIDO: 02/09/2012

ACEPTADO: 25/03/2013 